\title{
Hashimoto's Thyroiditis and Medullary Carcinoma of Thyroid
}

\author{
Senjuti Dasgupta, ${ }^{1}$ Sudipta Chakrabarti, ${ }^{2}$ Prakas Kumar Mandal, ${ }^{3}$ Shikha Das ${ }^{4}$ \\ 'Department of Pathology, Medical College, ${ }^{2}$ ESI PGIMSR, Manicktala, ${ }^{3}$ PGGE\&R, ${ }^{4}$ RG Kar Medical College and Hospital, \\ Kolkata, West Bengal, India.
}

\section{ABSTRACT}

Hashimoto's thyroiditis (HT) has been found to be associated with lymphoma, papillary carcinoma and Hürthle cell neoplasms of thyroid. In contrast, there are only a few reports of co-existence of HT with medullary carcinoma of thyroid. An overall prevalence of medullary carcinoma of only $0.35 \%$ has been reported in HT patients. Such a rare combination is being presented here. A 33 year old female presented with history of goiter for one year. Fine needle aspiration cytology (FNAC) of the swelling revealed cytological features suggestive of medullary carcinoma of thyroid. Histopathological examination of total thyroidectomy specimen revealed Hashimoto's thyroiditis along with medullary carcinoma of thyroid. Although Hashimoto's thyroiditis can uncommonly coexist with thyroid neoplasm, its association with medullary carcinoma is extremely rare and hence being presented.

Keywords: association, hashimoto's thyroiditis, histopathology, medullary carcinoma of thyroid.

\section{INTRODUCTION}

Hashimoto's thyroiditis (HT) is an organ -specific immune -mediated inflammatory disorder generically designated as autoimmune thyroiditis. Medullary thyroid carcinoma is a malignant tumor showing parafollicular C-cell differentiation. The association between HT with lymphoma, papillary carcinoma and Hürthle cell neoplasms of thyroid has been well documented. ${ }^{1}$ But there are only a few reports depicting a co -existence of the condition with medullary carcinoma of thyroid. ${ }^{2-}$ ${ }^{5} \mathrm{~A}$ prevalence of medullary carcinoma of only $0.35 \%$ has been reported in HT patients. ${ }^{6}$ One such exceptional case is being reported.

\section{CASE REPORT}

A 33 year old female presented with a swelling in front of neck for the last one year. Clinical examination suggested the origin of the swelling from thyroid gland. No family history of thyroid disease was elicited. Her thyroid hormonal status were as follows: $\mathrm{T}_{3}-1.2 \mathrm{ng} /$ $\mathrm{ml}$ (normal range 0.5 to $1.8 \mathrm{ng} / \mathrm{ml}), \mathrm{T}_{4}-7.1 \mu \mathrm{g} /$ $\mathrm{dL}$ (normal range 4 to $11 \mu \mathrm{g} / \mathrm{dL}$ ), TSH $-5.89 \mu \mathrm{U} / \mathrm{ml}$ (normal range 0.39 to $6.16 \mu \mathrm{U} / \mathrm{ml}$ ).

FNAC from thyroid swelling revealed spindle cells arranged in loose clusters and also singly. The nuclei of these cells had uniform, stippled nuclear chromatin. These features were suggestive of medullary carcinoma of thyroid (Figure 1).

Correspondence: Senjuti Dasgupta, Department of Pathology, Medical College, 88, College Street, Kolkata - 700073, West Bengal, India. Email: dasguptasenjuti@gmail.com, Phone: +919830510051. 
A total thyroidectomy was performed. Two lobes of thyroid measured $4 \times 2.5 \mathrm{~cm}$ and $2 \times 1.5 \mathrm{~cm}$ respectively. Cut surface was solid with grayish-brown and whitish areas (Figure 2).

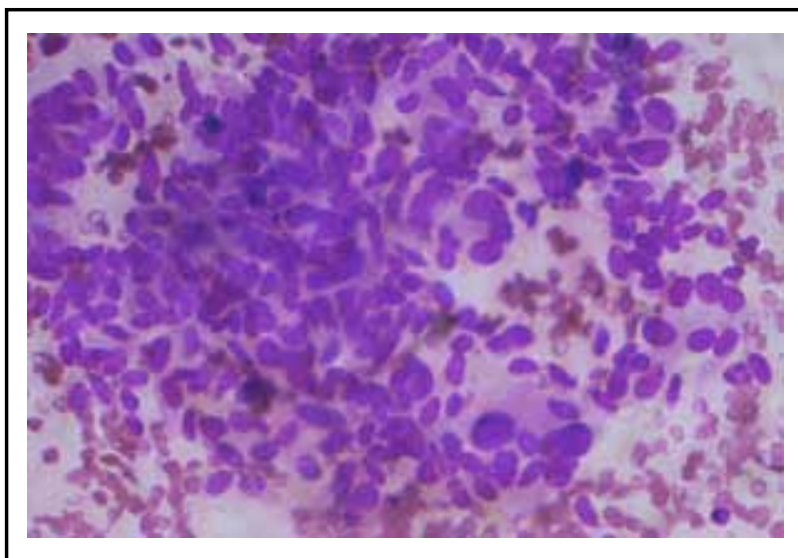

Figure 1. Cytologic smear showing spindle cells arranged in loose clusters and also singly. Colloid is scanty; Leishman\&Giemsa, $\times 400$.

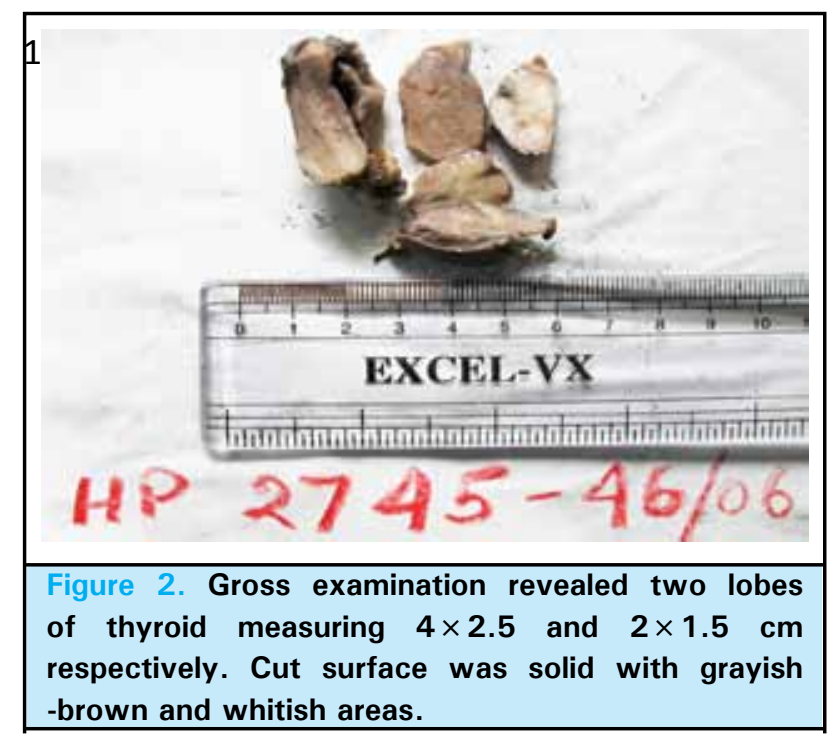

In hematoxylin and eosin (H\&E) stained sections, there were two distinct histological appearances of the lesion (Figure 3). In one area there was lymphocytic infiltration of the stroma and oncocytic change of the follicular epithelium. The lymphoid tissue exhibited large follicles with prominent germinal centre. In other areas, there were sheets of polygonal and spindle cells. The cells had vesicular nuclei with eosinophilic cytoplasm. In between cellular areas there were homogeneous, eosinophilic areas (Figure 4A), which were confirmed as amyloid in Congo red staining (Figure 4B).

The histopathological findings prompted us to advise the patient to undertake a test for anti-thyroperoxidase antibodies (anti TPO Ab), which is a sensitive marker for Hashimoto's thyroiditis. The anti TPO Ab level, performed in the immediate post-operative period, was found to be $510 \mathrm{lU} / \mathrm{ml}$ (normal range $<34 \mathrm{lU} / \mathrm{ml}$ ).

Based on these features, the lesion was diagnosed as medullary carcinoma of thyroid along with Hashimoto's thyroiditis.

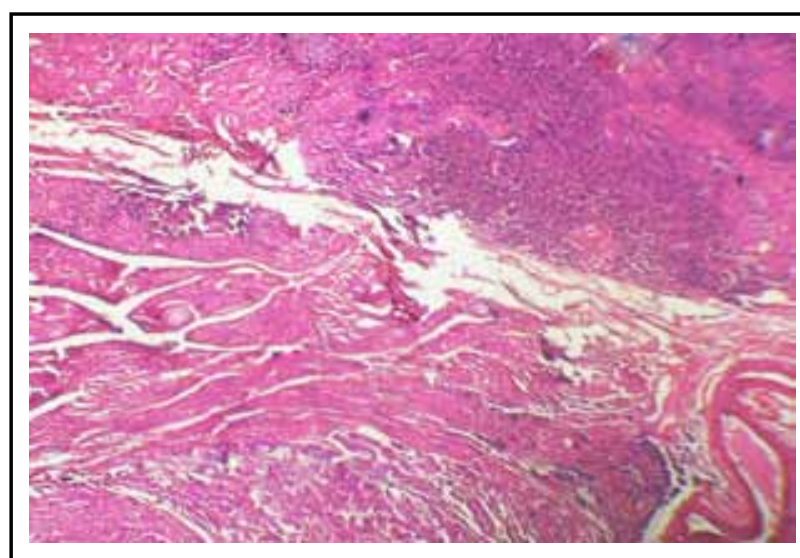

Figure 3. Photomicrograph showing areas of Hashimoto's thyroiditis (Top) along with areas of medullary carcinoma of thyroid (Bottom); H\&E, $\times 100$.

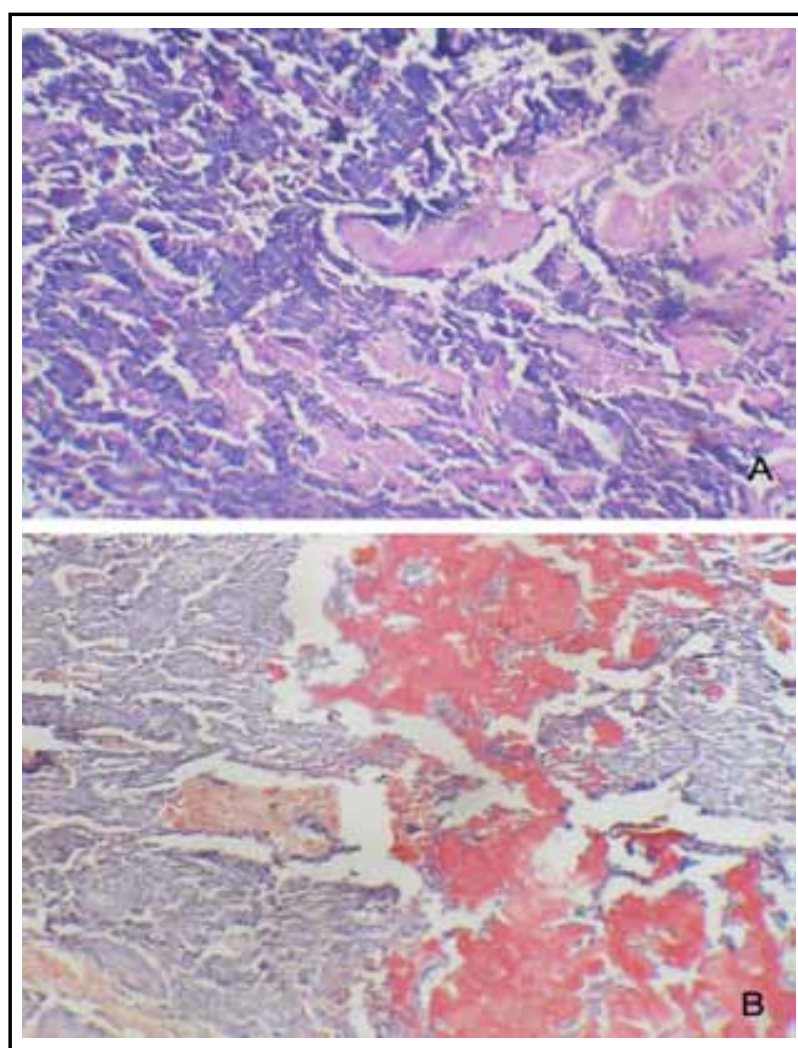

Figure 4 . (a) Photomicrograph showing homogeneous, eosinophilic areas of amyloid in between cellular areas of medullary carcinoma of thyroid; $H \& E$, $\times 100$; (b) Photomicrograph showing reddish colored amyloid; Congo red, $\times 100$. 


\section{DISCUSSION}

The report of association between thyroid cancer and HT has been documented by many studies. From a review of these studies, the incidence of thyroid carcinoma developing against a background of HT has been found to be between $0.5 \%$ and $23 \% .^{7}$ The most common malignancy found associated with HT is papillary carcinoma. ${ }^{1}$

The co -existence of medullary carcinoma and Hashimoto's thyroiditis is rare. The first well documented case of co-existence of these two entities in the same patient in the English literature was published in $1983 .^{2}$ Since then, only few sporadic cases have been reported. ${ }^{3-5}$ Schuetz et al. reported an overall prevalence of medullary carcinoma of $0.35 \%$ in HT patients. ${ }^{6}$ The pathogenesis of co-existence of Hashimoto's thyroiditis with neoplasms is a matter of debate. It is controversial whether HT predisposes to carcinoma or HT develops secondarily as an immune response to the malignancy. ${ }^{8}$ In one study it was stated that chronic stimulus of thyroid stimulating hormone (TSH) on thyroid tissue affected by autoimmune disease and progressively hypofunctioning could be the main factor responsible for development of neoplasia. ${ }^{9}$ However, another study concluded that the thyroiditis occurred in response to the medullary carcinoma and not vice versa. ${ }^{3}$

Selective surgical treatment of patients with clinical thyroiditis is indicated. The two most common characteristics prompting surgical intervention were the presence of a non-suppressing dominant nodule and a cold area in thyroid scan. ${ }^{7}$ Since serum calcitonin level is a sensitive marker of medullary carcinoma, a proposal has been made to routinely measure serum calcitonin in patients of $\mathrm{HT}$. In the rare occasion when these two conditions co-exist, raised serum calcitonin level would help to detect the malignancy at an early stage. ${ }^{6}$ In the present study, thyroidectomy was done for the management of medullary carcinoma and subsequently Hashimoto's thyroiditis was diagnosed, on the basis of biochemical and microscopic features. Elevated levels of antibodies against thyroglobulin and thyroperoxidase confirm the diagnosis of HT. A positive test for anti TPO Ab is one of the most sensitive indicators of HT. ${ }^{10}$

Though association between thyroid carcinoma and Hashimoto's thyroiditis is rare, the patients with thyroiditis should be operated when they develop a nodule to exclude the development of a malignancy.

\section{REFERENCES}

2. Rosai J, Ackerman. Thyroid gland. In: Rosai J,Ackerman, editors. Rosai and Ackerman's surgical pathology. $10^{\text {th }}$ ed. St. Louis: Elsevier; 2011. p. 488-564.

3. Weiss LM, Weinberg DS, Warhol MJ. Medullary carcinoma arising in a thyroid with Hashimoto's disease. Am J Clin Pathol. 1983;80:534-8.

4. Gaskin D, Parai SK, Parai MR. Hashimoto's thyroiditis with medullary carcinoma. Can J Surg. 1992;35:528-30.

5. De Pasquale L, Sommaruga L, Andreani S, Bastagli A. Hashimoto's thyroiditis and medullary carcinoma in the same gland: a purelyrandom occurrence? Chir Ital. 2004;56:557-62.

6. Mousa U, Gursoy A, Ozdemir H, Moray G. Medullary thyroid carcinoma in a patient with Hashimoto's thyroiditis diagnosed by calcitonin washout from a thyroid nodule. Diagn Cytopathol. 2013;41:644-6.
7. Schuetz M, Beheshti M, OezerS, Novotny C, Paul M, Hofmann A, et al. Calcitonin measurements for early detection of medullary thyroid carcinoma or its premalignant conditions in Hashimoto's thyroiditis. Anticancer Res. 2006;26:723-7.

8. Büyükaşık $O$, Hasdemir AO, Yalçın E, Celep B, Sengül $\mathrm{S}$, Yandakçı $\mathrm{K}$, et al. The association between thyroid malignancy and chronic lymphocytic thyroiditis: should it alter the surgical approach? Endokrynol Pol. 2011;62:303-8.

9. Cordioli MI, Cury AN, Nascimento AO, de Oliveira AK, Mello M, Saieg MA. Study of the histological profile of papillary thyroid carcinomas associated with Hashimoto's thyroiditis. Arq Bras Endocrinol Metabol. 2013;57:445-9.

10. Reda G, Cesareo R, Lolli E, Gargiulo A. Thyroid cancer and Hashimoto's thyroiditis. Minerva Chir. 1997;52:139-41.

11. Dayan CM, Daniels GH. Chronic autoimmune thyroiditis. N Engl J Med. 1996;335:99-107. 